\title{
Infertility, infertility treatment, and congenital malformations: Danish national birth cohort
}

\author{
Jin Liang Zhu, Olga Basso, Carsten Obel, Camilla Bille, Jørn Olsen
}

\begin{abstract}
Objectives To examine whether infertile couples (with a time to pregnancy of $>12$ months), who conceive naturally or after treatment, give birth to children with an increased prevalence of congenital malformations.

Design Longitudinal study.

Setting Danish national birth cohort.

Participants Three groups of liveborn children and their mothers: 50897 singletons and 1366 twins born of fertile couples (time to pregnancy $\leq 12$ months), 5764 singletons and 100 twins born of infertile couples who conceived naturally (time to pregnancy $>12$ months), and 4588 singletons and 1690 twins born after infertility treatment.

Main outcome measures Prevalence of congenital malformations determined from hospital discharge diagnoses. Results Compared with singletons born of fertile couples, singletons born of infertile couples who conceived naturally or after treatment had a higher prevalence of congenital malformations-hazard ratios 1.20 (95\% confidence interval 1.07 to 1.35 ) and 1.39 (1.23 to 1.57 ). The overall prevalence of congenital malformations increased with increasing time to pregnancy. When the analysis was restricted to singletons born of infertile couples, babies born after treatment had an increased prevalence of genital organ malformations (hazard ratio 2.32, 1.24 to 4.35 ) compared with babies conceived naturally. No significant differences existed in the overall prevalence of congenital malformations among twins.

Conclusions Hormonal treatment for infertility may be related to the occurrence of malformations of genital organs, but our results suggest that the reported increased prevalence of congenital malformations seen in singletons born after assisted reproductive technology is partly due to the underlying infertility or its determinants. The association between untreated infertility and congenital malformations warrants further examination.
\end{abstract}

\section{Introduction}

About $10-20 \%$ of couples who are trying to become pregnant have a waiting time to pregnancy longer than 12 months, the clinical definition of infertility in most industrialised countries. ${ }^{1}$ An increasing number of couples seek treatment for infertility, as reflected by the rising number of children born after assisted reproductive technology. ${ }^{2}$ Children conceived after assisted reproductive technology have an excess of congenital malformations compared with children conceived spontaneously,,$^{3-5}$ but little research has been devoted to attempting to separate the effect of assisted reproductive technology from that of infertility itself.
In a recent review, Rimm et al pointed out that previous studies on the topic have lacked a comparison group of children born of infertile couples who conceived naturally. ${ }^{5}$ Some of the determinants of infertility may share a common causal path with mechanisms that cause congenital malformations. Using a large cohort of Danish couples, we estimated the prevalence of congenital malformations as a function of infertility and its treatment.

\section{Methods}

We did the study within the Danish national birth cohort. ${ }^{6}$ From June 1997 to February 2003, 85381 women (92 892 pregnancies) responded during the first or second trimester to the first of four scheduled telephone interviews. Women were asked if their pregnancy was planned and how long they had tried to become pregnant before succeeding. Possible answers were: "right away," one to two months, three to five months, six to 12 months, and $>12$ months. If they reported a time to pregnancy of six months or longer, participants were also asked if they or their male partner had received any infertility treatment. Couples who reported a time to pregnancy of less than six months were not asked about treatment, and we classified them as not treated. We identified three groups of planned pregnancies: 52380 conceived by fertile couples (time to pregnancy $\leq 12$ months), 5910 conceived naturally by infertile couples ( $>12$ months), and 5564 conceived by infertile couples after infertility treatment. The first group comprised all couples with a time to pregnancy of $\leq 12$ months and no report of infertility treatment. The second group included all couples with a time to pregnancy of $>12$ months and no infertility treatment. The last group included all couples with a report of treatment for infertility before the pregnancy. If a woman contributed with more than one pregnancy, we included only the earliest.

If a woman reported that she or her male partner had received infertility treatment, she was then asked "what kind of infertility treatment did you or your male partner receive?" She could choose one or more of six specified forms of treatment and describe other types of treatment in free text. The specific treatments included intracytoplasmic sperm injection, in vitro fertilisation, intrauterine insemination, hormonal treatment, surgery (such as removal of adhesions or fibroid in fallopian tube), and hysterosalpingography (rinsing of fallopian tubes). Women who reported more than one procedure were classified according to the above priority sequence. We combined surgery and hysterosalpingography into one group and categorised an

An extra table is on bmj.com 
Table 1 Congenital malformations in singletons according to time to pregnancy (TTP) and infertility treatment

\begin{tabular}{|c|c|c|c|c|c|c|c|c|c|}
\hline \multirow{3}{*}{ Malformations } & \multirow{3}{*}{$\begin{array}{l}\text { No }(\%) \text { singletons } \\
\text { born of fertile } \\
\text { couples (TTP } \leq 12 \\
\text { months) (group A; } \\
n=50897 \text { ) }\end{array}$} & \multicolumn{3}{|c|}{$\begin{array}{l}\text { Singletons born of infertile couples who } \\
\text { conceived naturally (TTP>12 months) (group B; } \\
\qquad n=5764)\end{array}$} & \multicolumn{5}{|c|}{ Singletons born of infertile couples who received infertility treatment (group C; $\mathrm{n}=4588$ ) } \\
\hline & & \multirow[t]{2}{*}{ No $(\%)$} & \multicolumn{2}{|c|}{$\begin{array}{l}\text { Hazard ratio }(95 \% \mathrm{CI}) \text { with group } \\
\qquad \mathrm{A} \text { as reference }{ }^{*}\end{array}$} & \multirow[t]{2}{*}{ No $(\%)$} & \multicolumn{2}{|c|}{$\begin{array}{l}\text { Hazard ratio }(95 \% \mathrm{Cl}) \text { with group } \\
\qquad \text { as reference }{ }^{*}\end{array}$} & \multicolumn{2}{|c|}{$\begin{array}{c}\text { Hazard ratio }(95 \% \mathrm{Cl}) \text { with group } \\
\text { B as reference }{ }^{*} \dagger\end{array}$} \\
\hline & & & Crude & Adjusted‡ & & Crude & Adjusted‡ & Crude & Adjusted‡ \\
\hline All§ & $2564(5.0)$ & $344(6.0)$ & 1.19 & $1.20(1.07$ to 1.35$)$ & $307(6.7)$ & 1.35 & 1.39 (1.23 to 1.57$)$ & 1.13 & $1.17(1.00$ to 1.36$)$ \\
\hline Nervous system & $78(0.2)$ & $19(0.3)$ & 2.16 & $2.01(1.21$ to 3.34$)$ & $15(0.3)$ & 2.14 & 2.16 (1.23 to 3.80$)$ & 0.99 & 1.18 (0.59 to 2.35) \\
\hline $\begin{array}{l}\text { Eye, ear, face, } \\
\text { and neck }\end{array}$ & $180(0.4)$ & $30(0.5)$ & 1.48 & 1.45 (0.98 to 2.15) & $19(0.4)$ & 1.20 & 1.20 (0.74 to 1.94$)$ & 0.81 & 0.84 (0.47 to 1.51) \\
\hline $\begin{array}{l}\text { Circulatory } \\
\text { system }\end{array}$ & $494(1.0)$ & $71(1.2)$ & 1.27 & 1.25 (0.97 to 1.61) & $53(1.2)$ & 1.20 & 1.21 (0.91 to 1.62) & 0.94 & 0.92 (0.64 to 1.32$)$ \\
\hline $\begin{array}{l}\text { Respiratory } \\
\text { system }\end{array}$ & $92(0.2)$ & $9(0.2)$ & 0.86 & 0.77 (0.38 to 1.53) & $11(0.2)$ & 1.33 & 1.21 (0.64 to 2.28$)$ & 1.54 & 1.76 (0.72 to 4.32$)$ \\
\hline Cleft lip/palate & $117(0.2)$ & $16(0.3)$ & 1.21 & 1.15 (0.68 to 1.95) & $5(0.1)$ & 0.47 & 0.48 (0.19 to 1.18$)$ & 0.39 & 0.38 (0.14 to 1.06) \\
\hline Digestive system & $187(0.4)$ & $33(0.6)$ & 1.56 & 1.51 (1.04 to 2.19$)$ & $24(0.5)$ & 1.43 & 1.44 (0.94 to 2.22) & 0.92 & 0.94 (0.55 to 1.60) \\
\hline Genital organs & $172(0.3)$ & $15(0.3)$ & 0.77 & 0.81 (0.48 to 1.38) & $30(0.7)$ & 1.96 & 2.03 (1.37 to 3.01$)$ & 2.54 & 2.32 (1.24 to 4.35) \\
\hline Urinary system & $175(0.3)$ & $21(0.4)$ & 1.06 & 1.07 (0.68 to 1.69) & $24(0.5)$ & 1.53 & 1.45 (0.94 to 2.24) & 1.44 & 1.34 (0.74 to 2.43$)$ \\
\hline $\begin{array}{l}\text { Musculoskeletal } \\
\text { system }\end{array}$ & $1142(2.2)$ & $158(2.7)$ & 1.23 & 1.27 (1.07 to 1.51) & $147(3.2)$ & 1.45 & 1.54 (1.29 to 1.83$)$ & 1.18 & 1.23 (0.98 to 1.55$)$ \\
\hline $\begin{array}{l}\text { Other } \\
\text { malformations }\end{array}$ & $199(0.4)$ & $27(0.5)$ & 1.20 & $1.20(0.80$ to 1.80$)$ & $28(0.6)$ & 1.57 & 1.63 (1.09 to 2.44) & 1.31 & 1.34 (0.78 to 2.30) \\
\hline $\begin{array}{l}\text { Chromosomal } \\
\text { abnormalities } \\
\end{array}$ & $98(0.2)$ & $8(0.1)$ & 0.72 & 0.68 (0.33 to 1.41$)$ & $10(0.2)$ & 1.14 & 0.98 (0.50 to 1.89$)$ & 1.57 & 1.51 (0.59 to 3.87$)$ \\
\hline
\end{tabular}

†Analysis restricted to infertile couples.

$\ddagger$ Adjusted for maternal age at conception, pre-pregnancy body mass index, smoking, alcohol intake, coffee consumption, and occupational status.

$\S$ Children with two or more malformations counted once for all congenital malformations but counted for each malformation in relevant subgroup.

additional group as alternative treatments (for example, acupuncture, zone therapy, diet, or vitamins), on the basis of the free text description.

We linked the cohort to pregnancy outcomes by using the national hospital register and the medical birth register, ${ }^{78}$ by means of the unique civil registration number. We excluded pregnancies that ended in spontaneous abortion $(n=628)$, induced abortion $(n=116)$, hydatidiform mole $(n=11)$, or ectopic pregnancy $(\mathrm{n}=1)$ and pregnancies with unknown outcomes because of emigration or other reasons $(n=44)$. No differences existed in spontaneous abortion or induced abortion among the studied groups $(\mathrm{P}=0.13$ for spontaneous abortion; $\mathrm{P}=0.73$ for induced abortion). We further excluded all stillbirths $(n=209$; of these, 16 were of one twin, and four were of both twins) because of incomplete information on malformations and all triplets ( $\mathrm{n}=84$, all live births) owing to small numbers. The rate of stillbirth differed among the three groups $(0.3 \%$ for fertile couples, $0.4 \%$ for untreated infertile couples, and $0.5 \%$ for treated infertile couples; $\mathrm{P}=0.01)$. After these exclusions, 61249 singletons and 3156 twins remained available for analysis.

Diagnoses on congenital malformations (ICD-10 (international classification of diseases, 10th revision) Q00-Q99 codes) are recorded in the national hospital register. ${ }^{7}$ We excluded two minor malformations (accessory auricle (Q170) and pigmented nevus (Q825)) and three malformations with possible uncertain diagnoses (patent ductus arteriosus (Q250), undescended testis (Q53), and hip dislocation (Q650-6)).

\section{Statistical analysis}

We calculated hazard ratios for a diagnosis of congenital malformations by means of Cox regression models, with follow-up starting from the date of birth and ending at the time of the first diagnosis of a malformation (or a specific group of malformations for subanalyses), death, or the end of follow-up (9 November 2004), whichever came first. By using Cox regression model, we took into consideration the censoring related to differences in follow-up time and death. Information on death (within the first year of life) came from the medical birth register.
We did separate analyses for singletons and twins, by using the Huber-White sandwich estimator for correction of standard errors in the analyses involving twins. We did a test for trend for the effect of time to pregnancy on malformations by using time to pregnancy categories as ordinal numbers in the full model.

Potential confounders included maternal age at conception $(<25,25-29,30-34, \geq 35$ years), pre-pregnancy body mass index $(<25, \geq 25)$, smoking (yes, no), alcohol intake (yes, no), coffee consumption (yes, no), and occupational status (high (managers, professionals, and technicians), medium (clerks, service and sales workers, skilled agricultural workers, and craft workers), low (unskilled workers), students, and unemployed). We included an additional category in the models for missing information on pre-pregnancy body mass index $(\mathrm{n}=964,1.6 \%$ for singletons; $\mathrm{n}=42,1.3 \%$ for twins).

\section{Results}

The median follow-up time was four years from the time of birth. Of the 293 children who died during the first year of life, 125 $(42.7 \%)$ had a diagnosis of congenital malformations.

Compared with singletons born of fertile couples, singletons born of infertile couples had a higher prevalence of congenital malformations, regardless of treatment (table 1). Among singletons born of infertile couples who conceived naturally, we saw an increased prevalence of malformations of the nervous system, digestive system, and musculoskeletal system. Singletons born of couples who received infertility treatment had a similar pattern, as well as a higher prevalence of malformations of genital organs and "others" (see extra table on bmj.com for results on detailed diagnoses with two-digital codes in ICD-10). When we restricted the analysis to singletons born of infertile couples, we saw an excess only of genital organ malformations associated with treatment (table 1). We could not attribute this increase to any specific malformations of the genital organs.

Among singletons born of untreated couples, prevalence of congenital malformations increased with increasing time to 
Table 2 Overall congenital malformations in singletons conceived spontaneously or after treatment, according to time to pregnancy

\begin{tabular}{|c|c|c|c|c|c|c|}
\hline \multirow{2}{*}{$\begin{array}{l}\text { Time to pregnancy } \\
\text { (months) }\end{array}$} & \multicolumn{3}{|c|}{ Singletons conceived spontaneously } & \multicolumn{3}{|c|}{ Singletons conceived after treatment for infertility } \\
\hline & No & $\begin{array}{l}\text { No (\%) with } \\
\text { malformations }\end{array}$ & $\begin{array}{l}\text { Adjusted hazard ratio }(95 \% \\
\mathrm{Cl})^{*}\end{array}$ & No & $\begin{array}{l}\text { No (\%) with } \\
\text { malformations }\end{array}$ & $\begin{array}{l}\text { Adjusted hazard ratio (95\% } \\
\text { CI)* }\end{array}$ \\
\hline $0-2$ & 28039 & $1317(4.7)$ & 1.00 & - & - & - \\
\hline $3-5$ & 13096 & $712(5.4)$ & 1.16 (1.06 to 1.27$)$ & - & - & - \\
\hline $6-12$ & 9762 & $535(5.5)$ & 1.17 (1.06 to 1.30$)$ & 625 & $34(5.4)$ & 1.00 \\
\hline$>>12$ & 5764 & $344(6.0)$ & 1.29 (1.14 to 1.45$)$ & 3963 & $273(6.9)$ & 1.34 (0.94 to 1.92$)$ \\
\hline Test for trend & & & $P<0.0001$ & & & $P=0.107$ \\
\hline
\end{tabular}

*Cox regression; adjusted for maternal age at conception, pre-pregnancy body mass index, smoking, alcohol intake, coffee consumption, and occupational status.

pregnancy (table 2). We saw a similar, but not statistically significant, trend in singletons born of treated couples.

Table 3 and table 4 show congenital malformations in singletons born after different forms of infertility treatment. Compared with singletons born of fertile couples, children born after intracytoplasmic sperm injection, in vitro fertilisation, intrauterine insemination, hormonal treatment, or surgery had an increased prevalence of congenital malformations, with hazard ratios between 1.31 and 1.85 (table 4 ). When we restricted the analysis to infertile couples, only intracytoplasmic sperm injection was associated with a significantly higher overall prevalence of congenital malformations (hazard ratio 1.57, 95\% confidence interval 1.11 to 2.23). We saw a significantly increased prevalence of genital organ malformations $(4.39,1.58$ to 12.21$)$ and musculoskeletal system malformations (1.67, 1.01 to 2.76$)$.
Twins had an overall higher prevalence of congenital malformations than singletons $(7.0 \%$ v $5.2 \% ; \mathrm{P}<0.0001)$. However, we saw no significant association with infertility, infertility treatment (table 5), or type of treatment (data not shown).

We obtained similar results when we restricted our analyses to firstborn children or to children born at term (data not shown).

\section{Discussion}

\section{Malformations in singletons}

Singletons born of infertile couples, regardless of treatment, had a higher prevalence of congenital malformations than did children born of couples with a time to pregnancy of $\leq 12$ months, and the prevalence of congenital malformations

Table 3 Congenital malformations in singletons born after different types of infertility treatment. Values are numbers (percentages)

\begin{tabular}{|c|c|c|c|c|c|c|}
\hline Malformations & $\begin{array}{l}\text { Intracytoplasmic sperm } \\
\text { injection }(\mathrm{n}=398)\end{array}$ & $\begin{array}{c}\text { In vitro } \\
\text { fertilisation } \\
(\mathrm{n}=1483)\end{array}$ & $\begin{array}{c}\text { Intrauterine } \\
\text { insemination } \\
(\mathrm{n}=1331)\end{array}$ & $\begin{array}{c}\text { Hormonal } \\
\text { treatment }(n=1083)\end{array}$ & $\begin{array}{c}\text { Surgery or } \\
\text { hysterosalpingography }(\mathrm{n}=128)\end{array}$ & $\begin{array}{l}\text { Alternatives } \\
\quad(\mathrm{n}=165)\end{array}$ \\
\hline $\mathrm{All}^{*}$ & $35(8.8)$ & $98(6.6)$ & $86(6.5)$ & $71(6.6)$ & $10(7.8)$ & $7(4.2)$ \\
\hline Nervous system & 0 & $6(0.4)$ & $3(0.2)$ & $5(0.5)$ & 0 & $1(0.6)$ \\
\hline Eye, ear, face, and neck & $1(0.3)$ & $8(0.5)$ & $4(0.3)$ & $6(0.6)$ & 0 & 0 \\
\hline Circulatory system & $6(1.5)$ & $17(1.1)$ & $20(1.5)$ & $10(0.9)$ & 0 & 0 \\
\hline Respiratory system & $1(0.3)$ & 0 & $5(0.4)$ & $4(0.4)$ & 0 & $1(0.6)$ \\
\hline Cleft lip/palate & $0(0.0)$ & $3(0.2)$ & 0 & $2(0.2)$ & 0 & 0 \\
\hline Digestive system & $3(0.8)$ & $8(0.5)$ & $6(0.5)$ & $6(0.6)$ & $1(0.8)$ & 0 \\
\hline Genital organs & $5(1.3)$ & $10(0.7)$ & $9(0.7)$ & $5(0.5)$ & $0(0.0)$ & $1(0.6)$ \\
\hline Urinary system & $2(0.5)$ & $9(0.6)$ & $6(0.5)$ & $6(0.6)$ & $1(0.8)$ & 0 \\
\hline Musculoskeletal system & $17(4.3)$ & $47(3.2)$ & $43(3.2)$ & $29(2.7)$ & $6(4.7)$ & $5(3.0)$ \\
\hline Other malformations & $2(0.5)$ & $9(0.6)$ & $7(0.5)$ & $8(0.7)$ & $2(1.6)$ & 0 \\
\hline Chromosomal abnormalities & $1(0.3)$ & $4(0.3)$ & $1(0.1)$ & $4(0.4)$ & 0 & 0 \\
\hline
\end{tabular}

${ }^{*}$ Children with two or more malformations counted once for all congenital malformations but counted for each malformation in relevant subgroup.

Table 4 Hazard ratios* (95\% confidence intervals) of congenital malformations in singletons born after different types of infertility treatment

\begin{tabular}{|c|c|c|c|c|c|c|c|c|}
\hline \multirow{2}{*}{ Malformations } & \multicolumn{2}{|c|}{ Intracytoplasmic sperm injection } & \multicolumn{2}{|c|}{ In vitro fertilisation } & \multicolumn{2}{|c|}{ Intrauterine insemination } & \multicolumn{2}{|c|}{ Hormonal treatment } \\
\hline & Crude & Adjusted $\dagger$ & Crude & Adjusted $†$ & Crude & Adjusted $†$ & Crude & Adjusted $\dagger$ \\
\hline All & 1.80 & 1.85 (1.33 to 2.59$)$ & 1.35 & 1.41 (1.15 to 1.73$)$ & 1.30 & $1.33(1.07$ to 1.65$)$ & 1.32 & 1.31 (1.03 to 1.66$)$ \\
\hline Nervous system & - & - & 2.66 & 2.48 (1.05 to 5.85) & 1.47 & 1.44 (0.45 to 4.59$)$ & 3.03 & 2.79 (1.13 to 6.92$)$ \\
\hline Eye, ear, face, and neck & 0.74 & 0.74 (0.10 to 5.33) & 1.58 & 1.61 (0.78 to 3.33) & 0.86 & 0.87 (0.32 to 2.35) & 1.58 & 1.51 (0.67 to 3.42$)$ \\
\hline Circulatory system & 1.58 & 1.64 (0.73 to 3.68$)$ & 1.20 & 1.23 (0.75 to 2.01$)$ & 1.56 & 1.60 (1.02 to 2.51$)$ & 0.96 & 0.95 (0.51 to 1.78$)$ \\
\hline Respiratory system & 1.39 & $1.21 \quad(0.17$ to 8.72$)$ & - & - & 2.08 & 1.91 (0.77 to 4.72) & 2.05 & 1.88 (0.69 to 5.13$)$ \\
\hline Cleft lip/palate & - & - & 0.88 & 0.93 (0.29 to 2.96) & - & - & 0.80 & 0.77 (0.19 to 3.13$)$ \\
\hline Genital organs & 3.78 & 3.93 (1.61 to 9.61) & 2.04 & 2.24 (1.17 to 4.28$)$ & 2.02 & 2.07 (1.05 to 4.06$)$ & 1.37 & 1.35 (0.55 to 3.28$)$ \\
\hline Urinary system & 1.47 & 1.37 (0.34 to 5.53) & 1.78 & 1.65 (0.84 to 3.27$)$ & 1.31 & 1.25 (0.55 to 2.82) & 1.62 & 1.61 (0.71 to 3.65$)$ \\
\hline Musculoskeletal system & 1.95 & 2.04 (1.26 to 3.29$)$ & 1.45 & 1.56 (1.16 to 2.10) & 1.46 & 1.52 (1.12 to 2.07) & 1.20 & $1.21 \quad(0.84$ to 1.76$)$ \\
\hline Other malformations & 1.30 & 1.31 (0.33 to 5.31) & 1.57 & 1.64 (0.83 to 3.25$)$ & 1.35 & 1.35 (0.63 to 2.88) & 1.89 & $1.87(0.92$ to 3.80$)$ \\
\hline Chromosomal & 1.31 & 1.13 (0.16 to 8.10$)$ & 1.41 & 1.13 (0.41 to 3.10$)$ & 0.39 & 0.35 (0.05 to 2.52) & 1.92 & 1.90 (0.70 to 5.19$)$ \\
\hline
\end{tabular}

abnormalities

For overall malformations, adjusted hazard ratio=1.61 (0.86 to 2.99) for surgery or hysterosalpingography and 0.84 ( 0.40 to 1.76$)$ for alternatives.

${ }^{*}$ Cox regression; reference group=singletons born of fertile couples.

†Adjusted for maternal age at conception, pre-pregnancy body mass index, smoking, alcohol intake, coffee consumption, and occupational status.

fChildren with two or more malformations counted once for all congenital malformations but counted for each malformation in relevant subgroup. 
Table 5 Congenital malformations in twins according to time to pregnancy (TTP) and infertility treatment

\begin{tabular}{|c|c|c|c|c|c|c|c|}
\hline \multirow{3}{*}{ Malformations } & \multirow{3}{*}{$\begin{array}{l}\text { No }(\%) \text { twins born of fertile } \\
\text { couples (TTP } \leq 12 \text { months) } \\
\text { ( } n=1366)\end{array}$} & \multicolumn{3}{|c|}{$\begin{array}{l}\text { Twins born of infertile couples who conceived naturally } \\
\text { (TTP>12 months) ( } \mathrm{n}=100)\end{array}$} & \multicolumn{3}{|c|}{$\begin{array}{c}\text { Twins born of infertile couples who received infertility } \\
\text { treatment }(n=1690)\end{array}$} \\
\hline & & \multirow{2}{*}{ No (\%) } & \multicolumn{2}{|c|}{ Hazard ratio $(95 \% \mathrm{Cl})^{*}$} & \multirow{2}{*}{ No (\%) } & \multicolumn{2}{|c|}{ Hazard ratio $(95 \% \mathrm{Cl})^{*}$} \\
\hline & & & Crude & Adjusted† & & Crude & Adjusted† \\
\hline$\overline{\text { Allf }}$ & $102(7.5)$ & $11(11.0)$ & 1.46 & 1.53 (0.80 to 2.91$)$ & $107(6.3)$ & 0.85 & 0.90 (0.67 to 1.21$)$ \\
\hline Nervous system & $2(0.1)$ & 0 & - & - & $7(0.4)$ & 2.90 & 2.83 (0.60 to 13.41$)$ \\
\hline Eye, ear, face, and neck & $5(0.4)$ & $1(1.0)$ & 2.69 & 2.69 (0.33 to 22.15) & $3(0.2)$ & 0.49 & 0.45 (0.10 to 2.04) \\
\hline Circulatory system & $31(2.3)$ & $3(3.0)$ & 1.30 & 1.56 (0.49 to 4.97$)$ & $25(1.5)$ & 0.65 & 0.73 (0.42 to 1.29$)$ \\
\hline Respiratory system & $4(0.3)$ & 0 & - & - & $8(0.5)$ & 1.62 & 1.48 (0.42 to 5.18$)$ \\
\hline Cleft lip/palate & $7(0.5)$ & 0 & - & - & $2(0.1)$ & 0.23 & 0.25 (0.06 to 1.05$)$ \\
\hline Digestive system & $10(0.7)$ & $1(1.0)$ & 1.35 & 1.30 (0.15 to 11.07$)$ & $7(0.4)$ & 0.57 & 0.56 (0.19 to 1.62$)$ \\
\hline Genital organs & $11(0.8)$ & $2(2.0)$ & 2.43 & 3.31 (0.68 to 16.07) & $11(0.7)$ & 0.82 & 1.12 (0.45 to 2.80$)$ \\
\hline Urinary system & $5(0.4)$ & $3(3.0)$ & 8.21 & 11.50 (1.05 to 126.02) & $7(0.4)$ & 1.13 & 1.57 (0.30 to 8.26) \\
\hline Musculoskeletal system & $37(2.7)$ & $3(3.0)$ & 1.09 & 1.06 (0.33 to 3.41$)$ & $50(3.0)$ & 1.10 & 1.13 (0.71 to 1.78$)$ \\
\hline Other malformations & $12(0.9)$ & $1(1.0)$ & 1.14 & 1.24 (0.18 to 8.62$)$ & $9(0.5)$ & 0.60 & 0.64 (0.28 to 1.47) \\
\hline Chromosomal abnormalities & $3(0.2)$ & 0 & - & - & $2(0.1)$ & 0.54 & $0.41 \quad(0.05$ to 3.15$)$ \\
\hline
\end{tabular}

${ }^{*}$ Cox regression; reference group=twins born of fertile couples.

†Adjusted for maternal age at conception, pre-pregnancy body mass index, smoking, alcohol intake, coffee consumption, and occupational status.

fChildren with two or more malformations counted once for all congenital malformations but counted for each malformation in relevant subgroup.

increased with increasing time to pregnancy. The higher prevalence of malformations of the nervous system among infertile couples may be related to stress caused by infertility. ${ }^{9} 10$ We may have underestimated the risk of some congenital malformations, as we had no data on malformations for miscarriages, induced abortions after prenatal screening, or stillbirths. Infertile couples are more likely to have been offered prenatal screening if they receive treatment. However, we obtained similar results after excluding Down's syndrome and neural tube defects (the most common defects diagnosed at screening).

We found an increased prevalence of congenital malformations in singletons born after infertility treatment, which is consistent with three recent meta-analyses that showed a 30-40\% excess. ${ }^{3-5}$ Our results are also consistent with a previous Danish study in which a crude relative prevalence of 1.41 (0.96 to 2.09) was estimated for singletons after in vitro fertilisation. ${ }^{11}$ However, when we restricted the analysis to singletons born of infertile couples, treatment was associated with an increased prevalence only of genital organ malformations. This increase may be explained by the use of ovulation inducing drugs, common to most courses of infertility treatment. Some studies have reported an increased prevalence of hypospadias in boys born after in vitro fertilisation or intracytoplasmic sperm injection. ${ }^{12-14}$ Although infertile couples who conceive naturally may differ from those who seek infertility treatment in more than care seeking behaviour (including the cause or severity of infertility), they are a more appropriate reference group than fertile couples.

All conventional forms of infertility treatment correlated with a higher prevalence of congenital malformations, but this remained significant only for intracytoplasmic sperm injection when the underlying infertility was taken into account. Intracytoplasmic sperm injection is generally offered to couples with male infertility, and such treatment started in Denmark in $1994 .{ }^{11}$ The increased prevalence of malformations among singletons born after intracytoplasmic sperm injection may be confounded by the indication for treatment. Unfortunately, we do not have information on the clinical causes of infertility.

\section{Malformations in twins}

Compared with twins born of fertile couples, twins born after infertility treatment did not show a higher prevalence of congenital malformations, as previously reported. ${ }^{5}$

\section{Study methods}

About one third of all pregnant women in Denmark participated in the cohort during the study period. Selection bias may have affected our estimates if participation was associated with the exposure as well as the outcome. This is unlikely, however, as we recruited participants before the outcome of the pregnancy was known. Furthermore, singletons born of unplanned or partly planned pregnancies (excluded from this analysis) had a similar prevalence of congenital malformations $(5.0 \%)$ to those born of fertile couples.

The prevalence of congenital malformations in our study was slightly higher than previously reported. ${ }^{11}$ We believe that this illustrates the importance of having a longer follow-up time to allow malformations be diagnosed. Our results may partly reflect a shorter time to diagnosis of minor malformations in children born after assisted reproductive technology if they are more carefully examined. However, we found that the prevalence of balanic or penile hypospadias was similar among the three comparison groups, whereas the prevalence of penoscrotal or perineal hypospadias was higher in singletons born after treatment; Klemetti and colleagues reported similar observations. $^{14}$

Despite the large sample size, the number of children with specific malformations was small. We therefore grouped congenital malformations by organ systems. We lacked power to detect small increases in the prevalence of specific malformations. At the same time, a "positive" finding for a specific malformation should be interpreted with caution because we tested many associations. We excluded some minor malformations or malformations that are often misdiagnosed or related to preterm birth, and we used only hospital discharge diagnoses with documented high quality (predictive value $=88.2 \%$; completeness $=89.9 \%)^{16}$

As diagnosis of malformations is subject to misclassification, we mailed questionnaires to all mothers of children with possible malformations (whether reported by the mother as part of the third and fourth interviews of the Danish national birth cohort or coded with a $\mathrm{Q}$ code in the hospital register). ${ }^{17}$ These questionnaires, returned by about $40 \%$ of the sample, requested detailed information about the clinical findings and were used by one of the authors (CB) to diagnose the malformations. We used hospital diagnoses (available for the entire cohort) for our analyses, but we checked the results by using self reported data from 
the questionnaire. ${ }^{17}$ We obtained similar results for singletons born after infertility treatment, but the slightly higher prevalence of malformations seen among singletons born of infertile couples who conceived naturally was not seen, perhaps owing to lower participation in this group.

Infertility treatment is widely available in Denmark within both the public and private healthcare systems. ${ }^{18}$ The public system offers all infertile couples up to three in vitro fertilisation treatments free of charge. Some couples with a time to pregnancy of less than six months may have received infertility treatment, which could attenuate the risk estimates. We expect this to be a minor problem, as only $7 \%$ of women with times to pregnancy of 6-12 months reported treatment (compared with $45 \%$ of women with $>12$ months). The type of treatment was reported by the woman, but we believe that the risk of misclassification is limited, as most infertile women are aware of the treatment they received.

\section{Conclusions}

Our results indicate that, in order to properly evaluate the effects of assisted reproductive technology, infertile patients who conceived spontaneously should be used as a reference. Infertile couples should be offered prenatal screening, and research should be devoted to finding the mechanisms behind the association between congenital malformations and infertility or subfertility.

We thank Dionne Law, Donna Baird, and Clarice Weinberg for their valuable comments on the manuscript and Anne Vingård Olesen for statistical advice.

Contributors: JLZ, OB, CO, and JO contributed to the study design. CB did the congenital malformation questionnaire survey. JLZ analysed the data and drafted the manuscript. All authors contributed to the conception of the paper, interpretation of data, and subsequent revisions of the manuscript. JO is the guarantor.

Funding: JLZ is supported by a grant from the Danish Medical Research Council (No 271-05-0115). This research was also supported in part by the intramural research programme of the NIH, National Institute of Environ-

\section{What is already known on this topic}

Infertile or subfertile couples who conceive naturally have a high risk of adverse pregnancy outcomes, such as preterm delivery, stillbirth, and neonatal death

Singletons born of infertile couples after infertility treatment have a higher prevalence of congenital malformations, including hypospadias, than singletons conceived naturally

\section{What this study adds}

Infertility or subfertility seems to be associated with an increased prevalence of congenital malformations in offspring

The increased prevalence of congenital malformations seen in singletons born after infertility treatment is partly confounded by the indication for treatment

To assess the side effects of assisted reproductive technology, children conceived naturally by infertile couples are a more appropriate comparison group than children conceived naturally mental Health Sciences. The Danish National Research Foundation established the Danish Epidemiology Science Centre, which initiated and created the Danish national birth cohort. The cohort is furthermore a result of a major grant from this foundation. Additional support for the Danish national birth cohort comes from the Pharmacy Foundation, the Egmont Foundation, the March of Dimes Birth Defects Foundation, the Augustinus Foundation, and the Health Foundation.

Competing interests: None declared.

Ethical approval: The Danish Data Protection Agency granted authorisation for the implementation of the project (No 2005-41-5488), and the Danish National Birth Cohort Steering Committee granted authorisation for the use of data from the cohort (No 2005-10).

1 Juul S, Karmaus W, Olsen J. Regional differences in waiting time to pregnancy: pregnancy-based surveys from Denmark, France, Germany, Italy and Sweden. Hum Reprod 1999;14:1250-4

2 Wright VC, Schieve LA, Reynolds MA, Jeng G. Assisted reproductive technology surveillance-United States, 2002. MMWR Surveill Summ 2005;54:1-24.

3 Hansen M, Bower C, Milne E, de Klerk N, Kurinczuk JJ. Assisted reproductive technologies and the risk of birth defects-a systematic review. Hum Reprod 2005;20:328-38.

4 McDonald SD, Murphy K, Beyene J, Ohlsson A. Perinatal outcomes of singleton pregnancies achieved by in vitro fertilization: a systematic review and meta-analysis. J Obstet Gynaecol Can 2005;27:449-59.

5 Rimm AA, Katayama AC, Diaz M, Katayama KP. A meta-analysis of controlled studies comparing major malformation rates in IVF and ICSI infants with naturally conceived children. J Assist Reprod Genet 2004;21:437-43.

6 Olsen J, Melbye M, Olsen SF, Sørensen TI, Aaby P, Andersen AM, et al. The Danish national birth cohort-its background, structure and aim. Scand J Public Health 2001;29:300-7.

7 Andersen TF, Madsen M, Jørgensen J, Mellemkjær L, Olsen JH. The Danish national hospital register: a valuable source of data for modern health sciences. Dan Med Bull 1999;46:263-8.

8 Knudsen LB, Olsen J. The Danish medical birth registry. Dan Med Bull 1998;45:320-3. 9 Schmidt L. Psychosocial burden of infertility and assisted reproduction [comment]. Lancet 2006;367:379-80.

10 Hansen D, Lou HC, Olsen J. Serious life events and congenital malformations: a national study with complete follow-up. Lancet 2000;356:875-80.

11 Westergaard HB, Johansen AM, Erb K, Nyboe Andersen A. Danish national in-vitro fertilization registry 1994 and 1995: a controlled study of births, malformations and cytogenetic findings. Hum Reprod 1999;14:1896-902.

12 Silver RI, Rodriguez R, Chang TS, Gearhart JP. In vitro fertilization is associated with an increased risk of hypospadias. J Urol 1999;161:1954-7.

13 Källén B, Finnström O, Nygren KG, Olausson PO. In vitro fertilization (IVF) in Sweden: risk for congenital malformations after different IVF methods. Birth Defects Res A Clin Mol Teratol 2005;73:162-9.

14 Klemetti R, Gissler M, Sevón T, Koivurova S, Ritvanen A, Hemminki E. Children born after assisted fertilization have an increased rate of major congenital anomalies. Fertil Steril 2005;84:1300-7.

15 McDonald S, Murphy K, Beyene J, Ohlsson A. Perinatal outcomes of in vitro fertilization twins: a systematic review and meta-analyses. Am J Obstet Gynecol 2005;193:141-52.

16 Larsen H, Nielsen GL, Bendsen J, Flint C, Olsen J, Sorensen HT. Predictive value and completeness of the registration of congenital abnormalities in three Danish population-based registries. Scand J Public Health 2003;31:12-6.

17 Bille C. Oral clefts-occurrence and risk factors [PhD thesis]. Odense: Faculty of Health Science, University of Southern Denmark, 2005.

18 Nyboe Andersen A, Gianaroli L, Felberbaum R, de Mouzon J, Nygren KG. Assisted reproductive technology in Europe, 2001: results generated from European registers by ESHRE. Hum Reprod 2005;20:1158-76.

(Accepted 14 July 2006)

doi 10.1136/bmj.38919.495718.AE

Danish Epidemiology Science Centre, Department of Epidemiology, Institute of Public Health, University of Aarhus, DK 8000 Aarhus C, Denmark

Jin Liang Zhu research fellow

Epidemiology Branch, National Institute of Environmental Health Sciences, National Institutes of Health, Department of Health and Human Services, MD A3-05, USA

Olga Basso research fellow

Perinatal Epidemiological Research Unit, Department of Gynaecology and Obstetrics, Aarhus University Hospital, DK 8200 Aarhus N, Denmark Carsten Obel medical doctor

Center for the Prevention of Congenital Malformations, Institute of Public Health, University of Southern Denmark, DK 5000 Odense C, Denmark

Camilla Bille medical doctor

Department of Epidemiology, School of Public Health, UCLA, Los Angeles, CA 90095-1772, USA

Jørn Olsen professor

Correspondence to:J L Zhu zjl@soci.au.dk. 